\title{
VIOLÊNCIA E PODER NO DISCURSO PSIQUIÁTRICO: DA EXCLUSÃO SISTEMÁTICA ÀS SUBJETIVAÇÕES NORMATIVAS*
}

\author{
VIOLENCE AND POWER IN THE PSYCHIATRIC DISCOURSE: FROM \\ SYSTEMATIC EXCLUSION TO NORMATIVE SUBJETIVATIONS
}

\author{
Bernardo Salles Malamut e Celina Maria Modena \\ Fundação Oswaldo Cruz, Belo Horizonte, Brasil
}

Izabel C. Friche Passos

Universidade Federal de Minas Gerais, Belo Horizonte, Brasil

\begin{abstract}
Resumo
Este artigo versa sobre as relações de poder e o exercício da violência nos atos médicos de psiquiatras de um hospital psiquiátrico público brasileiro. Valendo-se das noções de poder disciplinar e biopoder em Foucault, e das contribuições de Hannah Arendt sobre o conceito de violência e política, busca-se compreender o modo como os entrevistados se posicionam frente ao discurso psiquiátrico e qual o lugar reservado nesse discurso para os pacientes. Verifica-se como o discurso psiquiátrico asilar sofreu transformações após o início da reforma psiquiátrica, passando da exclusão sistemática da loucura para o imperativo de inclusão social. Conclui-se que o exercício da política, tal como Arendt o compreende, pode apresentar uma terceira via discursiva para um novo avanço na reforma psiquiátrica.
\end{abstract}

Palavras-chave: poder; violência; saúde mental; hospital psiquiátrico; reforma psiquiátrica.

\begin{abstract}
The aim of this article is to study the power relations and the exercise of violence in the medical practices by psychiatrists who works in a public Brazilian psychiatric hospital of XX state, Brazil. Enlightened by Foucault's notions of disciplinary power and biopower and Hannah Arendt's contributions on the concept of violence and politics, the objective was to understand how the interviewees posit themselves in relation to psychiatric discourse, and what is the established place for the patients in that discourse. It is verified how the psychiatric discourse was transformed after the beginning of the psychiatric reform, moving from a systematic exclusion of madness to an imperative of social inclusion. It is concluded that the exercise of politics, in Arendt terms, can introduce a third discoursive way to a new improvement of psychiatric reform.
\end{abstract}

Keywords: power; violence; mental health; psychiatric hospital; psychiatric reform.

\section{Introdução}

Por ocasião do lançamento do "I Relatório Mundial sobre violência e saúde", somos lembrados que o século $\mathrm{XX}$ será recordado como aquele marcado pela violência (Krug, Dahlberg, Mercy, Zwi, \& Lozano, 2002). O tema, já tratado pelas ciências humanas há bastante tempo, só ganhou o devido reconhecimento como um problema de saúde pública no final da década de 1980 (Minayo, 1994), e apenas em 1996 passou a ser considerado um dos principais problemas de saúde pública no mundo (Krug et al., 2002; Minayo \& Souza, 1997-1998).

Entretanto, na área da "saúde mental", o assunto é bem anterior. Acusados de promotores de atos violentos ou sendo o principal alvo de terapêuticas bárbaras, os usuários do sistema de atenção à saúde mental atravessaram esses dois extremos de posições possíveis quanto ao fenômeno. Um dos principais objetivos da reforma psiquiátrica é o combate à violência, antes institucionalizada, através da inclusão social (Organização Pan-Americana de Saúde, Organização Mundial de Saúde, 2001; Sistema Único de Saúde, Conselho Nacional de Saúde, 2002). Porém, o imperativo de inclusão apresenta-se de forma tão normativa quanto a exclusão sistemática, da qual os loucos foram objeto. Dessa forma buscaremos a abertura para uma terceira via discursiva - a do exercício comunitário da política.

Situamos como um importante marco no processo epistêmico da reforma psiquiátrica a publicação 
da tese de Michel Foucault - História da loucura na idade clássica. Nessa obra, a hipótese da anexação da loucura à doença mental pela psiquiatria se afirmou (Foucault, 2000). Roudinesco, Canguilhem, Major e Derrida (1994) resumiram como Foucault, em sua tese, evidenciava a ação da psiquiatria como uma polícia dos loucos revestida de filantropia. Anos mais tarde, o próprio autor (Foucault, 2006c) elucidou que seu propósito nunca foi fazer um recenseamento dos mecanismos psiquiátricos asilares, nem mesmo traçar uma história da loucura; seu problema sempre foi o das relações entre sujeito e práticas de poder.

Concordamos com Deleuze (2010) quando ele sublinhou a atualidade de Foucault, e buscaremos aqui nos focar no que o autor disse ser "o problema de todo mundo: o do poder" (Foucault, 2006c, p. 225). Foucault nos lembrou ainda que "todas as grandes reformas, não só da prática psiquiátrica, mas do pensamento psiquiátrico, se situam em torno desta relação de poder; são tentativas de deslocar a relação, mascará-la, eliminá-la e anulá-la" (Foucault, 2009a, p. 124). Porém, não encontramos em Foucault uma teoria geral do poder (Maia, 1995). Como veremos, sua perspectiva é inovadora, já que não se centra nem no Estado como paradigma do poder, nem no Direito como modalidade negativa e reguladora.

Utilizaremos também das teorizações de Hannah Arendt, já que ela apresenta proximidades com a análise foucaultiana, além de trazer imensa contribuição quanto à diferenciação do exercício do poder para a prática da violência. Foi ela quem reiterou a afirmação de que o século XX pode ser considerado o século da violência. Sua perspectiva se afasta de tendências da psicologia contemporânea de naturalizar a violência através de conceitos psicanalíticos (Costa, 1986) ou da perspectiva psiquiátrica que toma a violência como uma manifestação psicopatológica (Bertolote, 2009). Para Arendt (2010), os fenômenos da violência e do poder localizam-se no âmbito político do agir humano.

A prática psiquiátrica contemporânea e, suas relações com o exercício de poder, é objeto de pesquisas na atualidade (Martins, 2008; Passos, 2009). Porém, ainda é escassa a literatura a respeito dos efeitos da reforma psiquiátrica nos atuais arranjos de relação de poder na prática médica nos dispositivos psiquiátricos hospitalares remanescentes. Encontramos artigos como o de Grandella (2002), que se propõe a analisar um hospital psiquiátrico remanescente através da pesquisa quantitativa e qualitativa. Contudo, o autor utiliza os conceitos de violência e poder de forma inespecífica, o que embaça a análise das possíveis intervenções a serem extraídas. Importante dizer que persistem no Brasil 208 hospitais psiquiátricos, totalizando 35.426 leitos (Ministério da Saúde, 2010). É uma evidência que de- marca o valor de pesquisas que se proponham a analisar a situação da prática médica nesses estabelecimentos públicos à luz dos princípios da reforma psiquiátrica.

O presente estudo teve como objetivo investigar os atuais arranjos de relação de poder e as incidências do discurso da reforma psiquiátrica sobre a prática de médicos trabalhadores de um hospital psiquiátrico público brasileiro.

\section{Metodologia}

Pautando-nos na noção foucaultiana de discurso como prática (Foucault, 2008a), e visando compreender a articulação entre um determinado contexto sócio-histórico e a implicação deste em uma produção discursiva, optamos por realizar uma pesquisa qualitativa (Deslandes \& Gomes, 2004; Minayo, 2008). Entendemos tratar-se de um conjunto de práticas que visam elucidar como a significação é significada (Charaudeau, 2008). Partimos da concepção de que a linguagem não é nem transparente, nem totalmente opaca, e que os discursos testemunham e sua análise elucida a interdependência entre a decantação de sentido e as condições de produção do discurso. Optamos pela leitura guiada pelos pressupostos da análise de discurso em sua modalidade francesa (Maingueneau, 1997; Rocha \& Deusdará, 2005), que, em linhas gerais, entende não haver uma dissociação entre o linguístico e o social, não sendo a linguagem uma "representação" ou suporte de um mundo pré-linguístico. Interessa ao pesquisador considerar o conjunto de enunciações produzidas pelos sujeitos pesquisados como "correlato de uma certa posição sócio-histórica na qual os enunciadores se revelam substituíveis" (Maingueneau, 1997, p. 14).

Desse modo, foi constituído um corpus a partir de nove entrevistas com médicos psiquiatras, trabalhadores de um hospital psiquiátrico público, realizadas no período de fevereiro a maio de 2010. Trata-se de uma amostra que não visa a uma representatividade numérica, mas sim a um aprofundamento analítico a partir do discurso de profissionais do campo. As entrevistas, semiestruturadas, seguiram as orientações de Minayo (2008) de manter um roteiro mental construído a partir do objeto pesquisado. Quatro perguntas guiaram as entrevistas: "quais são os critérios que você utiliza para encaminhar um paciente para internação?"; "como você lida com os pedidos de internação?"; "seu trabalho sofre influências da reforma psiquiátrica? Como?"; e finalmente, "como você avalia seu processo de tomada de decisões no cotidiano do serviço?". As entrevistas foram gravadas e transcritas na literalidade para a análise. O número de entrevistados foi obtido seguindo o critério de saturação, que dispõe que se devem entrevistar sujeitos até que a temática em exploração possa ser suficientemente discutida e teori- 
camente elucidada (Fontanella, Ricas, \& Turato, 2008). A pesquisa foi aprovada pelos Conselhos de Ética em Pesquisa das instituições envolvidas e seguiu todos os critérios estabelecidos pela Resolução 196/1996 do CNS/ MS (Conselho Nacional de Saúde, 2001).

Lembrando Foucault (2008a) quando ele nos apontou que não importa quem fala, mas que "o que ele diz não é dito de qualquer lugar" (p. 139), buscamos construir um corpus de entrevistas que tivesse maior representatividade e diversidade própria ao campo estudado. Desse modo, entrevistamos cinco mulheres e quatro homens, com idade variando entre 32 e 64 anos, sendo a média dos entrevistados de 51,5 anos. Quanto ao ano de formação e residência, buscamos também uma variação significativa, encontrando trinta e um anos de diferença entre o médico com mais tempo de formado e aquele com menor tempo de psiquiatria. Dois psiquiatras fizeram a residência na década de 1970, quatro na década de 1980 e três na década atual. Em relação ao tempo de trabalho no hospital pesquisado, encontramos grande amplitude, variando de trinta anos a cinco meses na unidade, com média de quatorze anos de trabalho. Todos os nomes dos entrevistados foram alterados para que sua identidade fosse preservada. Optamos pelo sistema em que a primeira letra do nome identifica o local de trabalho do entrevistado: " $\mathrm{A}$ " para psiquiatras trabalhadores da urgência/plantão, ou seja, local onde o primeiro atendimento será realizado; "C" para aqueles locados no setor de internação de curta permanência, em espaço aberto e com a presença de familiares acompanhantes; e, finalmente, "E" para a entrevistada trabalhadora da ala psiquiátrica de média permanência.

A escolha do hospital se deveu à ainda grande importância desse dispositivo na prática psiquiátrica, e ao fato de o hospital em questão ter como um de seus marcos de orientação para o trabalho as diretrizes da reforma. A unidade hospitalar em questão conta com 145 leitos instalados. Em 2009 recebeu um total de 9.037 pacientes provenientes de todo o estado em que se localiza, o que evidencia sua representatividade na assistência psiquiátrica pública do Estado. Ainda, o hospital é foco de várias pesquisas, e a unidade teve um papel importante no desencadeamento do processo de reforma psiquiátrica (Goulart, 2006; Goulart \& Durães, 2010; Moretzsohn, 1989; Passos, Goulart, Braga, Abreu, \& Vasconcelos, 2009).

Salientaremos ainda a importância da pesquisa sócio-histórica que antecedeu a ida ao campo, o que nos garantiu que nossas categorias analíticas fossem construídas seguindo as indicações de Charaudeau e Maingueneau (2008, pp. 43-46) articulando texto e contexto.

Orientados por Foucault (2008a), não buscamos atravessar os textos das entrevistas em busca de um sentido oculto, nem visamos a transformar as falas registradas em signos de outra coisa. Assim, manteremos a consistência e complexidade própria ao discurso, ou como nos disse o autor (2008a, p. 85): "não procuraremos, pois, passar do texto ao pensamento, da conversa ao silêncio, do exterior ao interior, da dispersão espacial ao puro recolhimento do instante, da multiplicidade superficial à unidade profunda. Permaneceremos na dimensão do discurso". Visamos, como disse Foucault, "determinar qual é a posição que pode e deve ocupar todo indivíduo para ser seu sujeito" (2008a, p. 108).

\section{Resultados e discussão}

A temática da violência emergiu em todas as entrevistas realizadas. Importante demarcar que $a$ priori essa não era uma categoria analítica da pesquisa, sendo construída a partir da recorrência do tema no corpus coletado. Focaremos nossa análise nos três principais atos que são exclusivamente médicos: internar, prescrever e dar alta. Neles percebemos uma oscilação entre as estratégias de poder e o exercício da violência.

\section{Os usos da internação: sobre como assumir a vida do outro}

O hospital não apresenta critérios predeterminados para orientar os psiquiatras sobre quando internar, e, assim sendo, os motivos escolhidos para a tomada de decisão são particulares. Porém, quando analisamos os textos produzidos pelos entrevistados em situação de entrevista, percebemos algumas regularidades discursivas importantes, que demarcam um lugar discursivo para os pacientes e outro para os médicos.

Os entrevistados relatam que o principal critério utilizado no momento em que há uma decisão por internar um paciente contra sua vontade é a "velha e conhecida" noção de risco (Delgado, 1992; Foucault, 2002, 2010a). Esse risco é uma noção imprecisa que responde muito mais a uma política de normalização da cidade e da família do que efetivamente a alguma violência potencial ou real por parte do paciente envolvido. Como disse Foucault (2010, p. 137): "Ser perigoso não é um delito. Ser perigoso não é uma doença, não é um sintoma. ... o perigo não é uma noção psiquiátrica". Na instabilidade do saber psiquiátrico, apesar dos esforços neurobiológicos e farmacológicos, trata-se daquilo que Foucault (2006b) apontou: "há a vontade dos psiquiatras de fundar sua prática em algo como uma defesa social, pois eles não podem fundá-la em verdade" (p. 320).

Camila, por exemplo, cita o risco como principal critério utilizado, e diz que só não interna quando "ele [o paciente] não apresenta risco de nada, que se ele tiver uma ligeira... indicação de risco, ... é um respaldo que 
você tem". E, ironicamente rindo, acrescenta - comentando sobre a impossibilidade de os pacientes discutirem suas decisões: "E psicótico tem voz? Tem! Aquela que ele escuta, que ele alucina. Ele não tem condições de escolha, né?! Não essas escolhas". Arnaldo, há quatro anos no plantão, relata que também dialoga muito pouco com os pacientes quando estes chegam ao hospital, pois: "90\% dos pacientes são inabordáveis". Arnaldo irá decidir, portanto, baseado na observação do paciente, e com isso acaba "pesando o risco". Alberto, trabalhador recém-chegado ao hospital, diz que a decisão de internar cabe a ele, já que "paciente não tem condições de decidir por essas questões". Segundo a descrição por ele dada, os pacientes psiquiátricos que chegam ao hospital não são marcados pelos signos do discurso médico-biológico, mas sim portadores de insígnias próprias ao rebotalho social: "pacientes agitados, agressivos, alcoolizados, pacientes perigosos, presidiários, pacientes que já mataram, pacientes que podem matar".

Célio, trinta anos de psiquiatria, afirma: "[o paciente] nunca vai deixar de se colocar em risco e colocar outras pessoas". Aline, recém-formada, diz também que "não vai adiantar eu entrar em debate com ele [o paciente]", já que esse sujeito que se dirige ao hospital "chega no limite ... É esse paciente que está totalmente desagregado, perdido, agredido, geralmente um monte de boletins de ocorrência, geralmente é aquele psicótico que está assim, tumultuando a cidade, que ninguém está conseguindo medicar". Cássia, mais de vinte anos de trabalho no hospital estudado, confirma que a internação responde a uma demanda social ao apontar que opta pela internação somente quando o paciente traz intensa "mobilização" ao serviço. Quando aprofundamos no texto de sua entrevista, esclarece-se que o que está em foco é a mobilidade desses sujeitos "muito maltratados, muito largados, esse povo geral mesmo" que "[tem] uma vida muito limitada, muito trancada", e com isso conclui que "não dá para largar o povo sozinho na rua, é complicado". Aline confirma ao dizer que os loucos "não são sociais. Não são pessoas de andar na rua".

Finalmente, Arthur, trabalhando há mais de dez anos na urgência e plantão do hospital, diz ainda que a decisão pela internação de um paciente "mais que em outras clínicas, é uma decisão muito mais circunstancial do que nosográfica".

Assim, percebemos um manejo populacional realizado pela psiquiatria. É Arthur quem esclarece sobre esse ponto, quando diz que decisões supostamente diagnósticas respondem a uma demanda social de controle e normalização dos homens infames - como diria Foucault (2006c), porque "se for levar tudo para a cadeia é complicado", diz o entrevistado. Desse modo, segundo Arthur, a psiquiatria "acaba funcionando como um amortecedor", e explica: "o próprio Estado joga para a psiquiatria, porque a psiquiatria [faz] seu amálgama para não ter superlotação penitenciária, ou para não ter impactos eleitorais maiores...".

Alberto é mais radical quanto a esse ponto e faz uma leitura diferente, pois coloca o psiquiatra no lugar de "usado" frente a um poder social que lhe escapa. Ele diz: "o manicômio é fruto da sociedade, não da psiquiatria. É a sociedade que abandona seus doidos, e ela continua querendo abandonar". Ele comenta ainda como todas as atrocidades ocorridas em Barbacena/MG, "em nome da razão" (Ratton, 1979), nada tinham a ver com a psiquiatria. Para ele,

isso revela um desconhecimento muito grande, na cabeça de muita gente, tá associando manicômio com a psiquiatria, tá associando o manicômio com métodos cruéis. Desconhecimento... E o pobre do psiquiatra? Quê que podia fazer se não tinha, não tinha pra quem retornar esse paciente? Será que o psiquiatra foi artifice disso aí? Eu acho que não. ... O psiquiatra é o último baluarte nisso, onde não tem mais jeito.

E chega a relatar um caso recente de um paciente em tratamento que faleceu nas mãos de um psiquiatra que, ao seu ver, medicou o paciente equivocadamente. No entanto, ele diz: "porque na verdade, eu não sei se você se dá conta disso, não foi ele quem prescreveu. Ele fez uma receita. Foi o sistema que prescreveu...".

Percebemos, portanto, como a sustentação e garantia da decisão pelo ato de internação é obtida através do lugar construído para o paciente no discurso dos médicos entrevistados. Predominantemente negativizados e objetificados, os pacientes tornam-se figuras potencialmente violentas; dessa forma, qualquer ato médico realizado nesse momento, por mais violento que seja, estaria justificado. Elaine diz: "é terapêutico ter uma certa oposição ao desejo do paciente", ao que Arthur completa: "em psiquiatria, quem faz o que o sujeito quer ... é charlatanismo, porque o querer dele está deformado". Trata-se, portanto, do caráter instrumental da violência. Como disse Hannah Arendt (2010, p. 68): "a violência é por natureza instrumental; como todos os meios, ela sempre depende da orientação e da justificação pelo fim que almeja. E aquilo que necessita de justificação por outra coisa não pode ser essência de nada". O psiquiatra não estaria, portanto, implicado em seu ato, na medida em que este seria nada mais do que um instrumento nas mãos de um poder maior: o Estado e sua intolerância com os indivíduos desviantes.

Porém, essa concepção de poder do Estado ignora três fatos fundamentais: a ideia de que o poder é relacional; a noção de distinção relacional expressa como relação de proporcionalidade entre poder e violência (Duarte, 2010); e, por fim, a concepção do poder como unicamente macroestrutural, desconhecendo a força da biopolítica microfísica das relações. 
O poder relacional: o jogo entre a família e o paciente

A violência justifica-se remetendo a um fim que jaz no futuro: uma terapêutica que visa ao "bem" do sujeito ou que almeja uma harmonização social. No entanto, como Arendt (2010, p. 67) marcou, não existe ou jamais existiu governança exclusivamente baseada nos meios da violência, visto que a violência pode ser justificável, mas nunca será legítima. Portanto, o ato clínico de internar não pode ser unicamente um ato violento, pois se assim o fosse, não seria um ato clínico e sim unicamente uma violência, como um sequestro ou prisão do corpo de um outro. A busca pela legitimidade nos leva à temática do poder, pois “o poder não precisa de justificação, sendo inerente à própria existência das comunidades políticas; o que ele realmente precisa é de legitimidade" (Arendt, 2010, p. 69). Se a violência se justifica como uma resposta demandada pelo Estado à psiquiatria, calcada no sintagma de Talião, o poder será legitimado pelo discurso dos familiares dos pacientes.

Seis dos nove entrevistados confirmam que a demanda por uma internação psiquiátrica é atravessada pela presença e discurso dos familiares. O familiar é o ator que, no processo de internação, tem o poder de questionar ou se opor ao ato médico. O psiquiatra não tem poder à revelia da família, já que esta, por não ser marcada pelos signos da "loucura" ou da "psicose", pode avaliar a decisão médica. Entretanto, veremos a menção de um caso em que o familiar, ao discordar da decisão pela internação, é taxado de "sem crítica". Impressiona que, em todos os outros relatos, "a família dá o voto de confiança que talvez essa [decisão de internar] seja uma solução", diz Camila.

Os entrevistados relatam sofrer pressão dos familiares para internar seus doentes, como diz Arthur: "[a gente] sofre muita pressão para internar. Geralmente pressão do grupo de suporte do paciente para internar e pressão do paciente para não ser internado". Arthur ainda confessa que a internação "é uma proteção para ele [paciente], e às vezes até mais para a família do que para ele". Célio experimenta a mesma pressão: "a família te pressionando para manter e o jovem te pressionando para dar alta", e justifica a atitude dos familiares: "claro que o familiar sofre e o paciente causa esse sofrimento a si e a outros". Camila é quem comenta mais claramente como isso reflete em sua decisão pela internação assumindo que "cede um pouquinho" em sua avaliação clínica, e é capaz de deixar o paciente que não tem necessidade de internação "um, dois dias internado" para deixar "a família mais tranquila".

$\mathrm{O}$ efeito dessa negociação é o já mencionado ganho de confiança, ou melhor dizendo, a legitimação do ato médico. Alberto chega a ser condescendente com o abandono quando menciona que "a família, muitas vezes para se livrar daquele doente, muitas vezes não sem razão [0 abandona]". Percebemos, portanto, como a internação acontece com frequência como uma resposta a uma demanda familiar: "a família tem de respirar", diz Arthur.

Mas a família também pode se opor ao ato médico, desvelando a violência deste ato ao internar alguém contra sua própria vontade. É Aline quem menciona o fato, e comenta que isso se deve a uma falta de crítica da própria família, e pensa que deveria haver "um órgão jurídico, dando respaldo pra tá avaliando isso aí mesmo sem autorização da família", e se pergunta: "como é que a família assume a vida do outro?”. Porém, ao enunciar, a frase retorna para ela mesma, promovendo um efeito de reflexão: "mas como é que o médico assume a vida do outro?". A família acaba sendo sempre apontada como legitimadora do ato médico, quando o solicita, claro está, mas também quando o recusa, pois neste segundo caso o estaria fazendo por ignorância de sua necessidade, da qual, aí sim, o médico detém o conhecimento.

\section{Repetição do jogo de poder: a alta.}

A cura sempre foi um problema para a psiquiatria. A ausência de critérios biológicos implicou em noções de cura fortemente marcadas pela ideologia social dominante. E cada época teve a sua. Mas a busca da "adaptação social" sempre esteve presente. Célio menciona como "cura... é zero por cento". Com isso, no momento da alta e no momento das prescrições, o trabalho feito é o de ser "um imperativo cultural ... por mais pejorativo que pareça, toda terapêutica acaba visando isso aí. Uma certa normalização", menciona Arthur.

Foucault (2006b) nos apontou como a cura, ao longo da história, se apresentou como um verdadeiro campo de batalha em que seria necessário dominar a força desmedida do doente. O que se passava no início da terapêutica da loucura (1810-1830), segundo Foucault (2006b, p. 12), era uma "cena de enfrentamento" de duas vontades (a do louco versus a do médico), em que a cura seria obtida finalmente através da confissão do próprio louco de sua "loucura". A submissão à força e à moral dos médicos (vontade e poder do outro) seriam a garantia da reconstituição do saber médico e, consequentemente, da cura.

Essa estrutura se mantém no hospital pesquisado na medida em que é exigida do paciente a submissão comportamental à vontade do outro institucional encarnado na figura do médico. Célio nos explica como funciona esse mecanismo na alta:

eu falo: 'tem que ter motivos pra te dar alta. Isso aqui quem vai me dar é você. Então, se vocêficar tranquilo, ai eu tenho aqui, está escrito justificativa da alta e eu vou ter uma justificativa para te dar alta. Agora, se vocêficar agitado, agressivo, eu não tenho justificativa 
para te dar alta. Você vai ficar aqui'. Aí geralmente eles se seguram e começam a se comportar melhor.

Aline é quem melhor elucida esse ponto, marcando a passagem do ato violento de internar alguém contra a própria vontade para a validação do ato como clínico. Vimos como os entrevistados inicialmente não se dedicam a conversar com os pacientes, em especial no momento em que eles chegam ao hospital: "na hora da urgência lá, você não explica nada, não dá tempo, urgência não se explica nada, se faz", diz Aline. Ao longo da internação, a situação se repete; quando pacientes buscam por ela no intuito de conversar sobre a alta, ela diz "vou enrolando, vou fugindo ... ou falo assim 'oh, vamos fazer o seguinte, mais tarde eu te avalio de novo' e dou uma esquecida ... aí dou uma sumida e depois o paciente esquece...". Com isso, "não fica uma imagem boa realmente, pro paciente, e até pra família mesmo isso é complicado". No momento da alta, a entrevistada irá se dedicar a uma conversa longa com o paciente, conversa claramente situada em um discurso de convencimento que visa "tratar" da violência antes exercida, apontando como isso foi feito "para ajudar". E diz mais: "ele [paciente] elabora isso pra gente", apontando como a função da elaboração não visa à suposta conscientização do paciente, mas sim a sanção do ato médico para o médico. Ela cita como procede com o paciente, dizendo: " $o h, a$ gente te amarrou, te sedou, a gente fez isso não foi porque a gente tava a fim de te sacanear não, a gente tava cuidando, a gente tava protegendo". E o que ela diz visar com isso? "Uma outra ideia da psiquiatria ... uma ideia positiva daquilo ali, que aqui é necessário, que dessa forma o paciente não vai fugir da psiquiatria". Ou seja, no momento da alta, a saída do hospital é novamente a entrada no discurso psiquiátrico que faz da loucura uma doença, conforme reiterava Foucault:

Por que não se pode sair do asilo? Não se pode sair do asilo, não porque a saída esteja longe, mas porque a entrada está demasiada próxima. Não se cessa de entrar no asilo, e cada um desses encontros, cada um desses afrontamentos entre o médico e o doente recomeçam, repetem indefinidamente esse ato fundador, esse ato inicial que é aquele pelo qual a loucura vai existir como realidade e o psiquiatra vai existir como médico. (Foucault, 2006b, p. 349)

O buscado não é uma solidez biológica, e sim "a estabilidade social mínima. Não dá pra largar o povo sozinho na rua" disse Cássia. É a expansão da psiquiatria à biopolítica da vida, ou como disse Foucault (2006a) em um texto cujo titulo "O asilo ilimitado" é bastante sugestivo para compreendermos a fala acima, trata-se da continuação de um projeto de sentinela de uma ordem social. Como nos diz Alberto, em sua visão, "a sociedade precisa de conhecimento psiquiátrico eficaz. ... Temos medicações muito boas hoje, porque a psiquiatria evolui a cada dia. Isso é um fato, não vai ter jeito. Ninguém vai barrar a psiquiatria".

\section{O poder psiquiátrico: não há paciente à revelia de si mesmo}

Contudo existem resistências, pois "se não houvesse possibilidade de resistência - de resistência violenta, de fuga, de subterfúgios, de estratégias que invertam a situação -, não haveria de forma alguma relações de poder" (Foucault, 2010a, p. 277). E se nos limitássemos à leitura de que as únicas fontes de legitimidade dadas ao poder médico fossem a família, que ganha sua parcela de "descanso", e o Estado, que assim evita superlotação de estruturas judiciário-policiais, abordaríamos o assunto sobre uma perspectiva reducionista e segregacionista, pois efetivamente não conseguiríamos compreender quando Camila diz: "psiquiatria é exatamente aquela [medicina] em que eu preciso do paciente. Eu não mando no paciente. Eu não consigo medicar o paciente se eu não levá-lo como um indivíduo que está na minha frente e que não é uma doença que está na minha frente". Como entender esse ponto?

Delineia-se, portanto, uma tese fundamental de Foucault:

Só é possível haver relações de poder quando os sujeitos forem livres. Se um dos dois estiver completamente à disposição do outro e se tornar sua coisa, um objeto sobre o qual ele possa exercer uma violência infinita e ilimitada, não haverá relações de poder. (2010a, p. 276)

Percebemos, portanto, como a violência em Foucault e em Arendt é resultado de uma ação de aniquilação do outro enquanto alteridade, conservando um sentido negativo e moral (Ortega, 2003-2004; Passos, 2008, 2010). Como disse Foucault (1995, p. 243): "uma relação de violência age sobre um corpo, sobre as coisas; ela força, ela submete, ela quebra, ela destrói; ela fecha todas as possibilidades; não tem, portanto, junto a si, outro polo senão aquele da passividade". Foi Duarte (2010) quem nos apontou como a relação entre violência e poder é composta em termos de uma relação de proporcionalidade: "quanto mais poder, menos violência, quanto mais violência, menos poder" (p. 135).

Camila assume que medicar à revelia do sujeito é uma prática "autoritária", mas é seu "compromisso com a comunidade". Aline concorda que existem procedimentos "é... como se diz... assim... agressivos". E Alberto diz que também faz muito uso de medicação contra a vontade do paciente, mas se recusa a explicar ao pesquisador o motivo para tal, apontando que somente os psiquiatras entendem o porquê. E Arnaldo conclui:

ele [o paciente] tem de sentir que ele é, que a coisa ali está sendo feita de acordo com o que ele tá pedindo ... 
na medida em que há, esse, vamos dizer, esse cerco, entre aspas, logo no início [do tratamento] a coisa vai melhorar.

Novamente, entre a opção pela violência, os psiquiatras entrevistados preferem a liberdade do paciente. Usam do instrumental violento para conseguir poder, mas, nesse ponto, retomamos Arendt (2010), quando ela nos ensinou que "a violência pode destruir o poder; ela é absolutamente incapaz de criá-lo" (p. 74). É fazendo com que o paciente sinta-se escutado, sinta-se compreendido, enfim, sinta-se livre, é assim que ele é aprisionado nas malhas do discurso psiquiátrico.

Entretanto, faremos aqui um giro, já que Foucault nos ensinou que o poder não é somente uma força que proíbe, coage ou reprime.

O que faz com que o poder se mantenha e seja aceito é simplesmente que ele não pesa só como uma força que diz não, mas que de fato ele permeia, produz coisas, induz ao prazer, forma saber, produz discurso. Deve-se considerá-lo como uma rede produtiva que atravessa todo o corpo social muito mais do que uma instância negativa que tem por função reprimir. (Foucault, 2009a, p.8)

O poder é, portanto, produtor de discursos e subjetividades, ou como disse Machado (2009, p. XX), "o poder disciplinar não destrói o indivíduo; ao contrário, ele o fabrica. $\mathrm{O}$ indivíduo não é o outro do poder, realidade exterior, que é por ele anulado; ele é um dos seus mais importantes efeitos". Desse modo, a disciplina será mais bem sucedida na medida em que contar com a adesão do sujeito (Passos, 2010). Isso nos leva aos pacientes. Na visão dos entrevistados, o que faz com que alguns pacientes busquem ativamente o hospital psiquiátrico e o discurso hegemônico da psiquiatria lá reinante?

É através do discurso de Alda que se evidencia algo em relação à posição dos pacientes:

[os pacientes] vão para os serviços muitas vezes para manter o estatuto de doentes, porque com o status de doentes elas podem sobreviver, com o medicamento que elas trocam, vendem, com a passagem de ônibus gratuita que permitem elas circularem para resolver outros problemas familiares, que sem isso elas teriam de fazer à pé, elas têm auxílio doença, elas visam uma aposentadoria porque ela sabe que depois de uma insatisfação de ter vivido um avilte qualquer no serviço, ou às vezes até pela própria condição dela mesma, se ela voltar para o trabalho ela vai ser demitida depois do afastamento, porque como não há especificidade de mão de obra, você pode trocar de qualquer jeito, porque tanto faz se é José, Pedro, Joaquim... eles vão fazer a mesma coisa...

Vemos como o processo de normalização responde a uma ordem capitalista e segregadora que ainda não deu lugar a outras formas de manifestações da subjetividade. E mais ainda, fica claro como não se trata de um consentimento, renúncia à liberdade ou transferência de direitos por parte dos pacientes. Não cairemos ainda no discurso psicanalítico do "ganho secundário", que aponta sobre a satisfação em um sintoma. Optamos pela interpretação foucaultiana que enfatiza como, na subjetivação de uma identidade de doente mental, trata-se de um problema prioritariamente político. É a confirmação da tese biopolítica de Foucault (2009a, p. 80):

O controle da sociedade sobre os indivíduos não se opera simplesmente pela consciência ou pela ideologia, mas começa no corpo, com o corpo. Foi no biológico, no somático, no corporal que, antes de tudo, investiu-se a sociedade capitalista. O corpo é uma realidade biopolítica. A medicina é uma estratégia biopolítica.

Sua tese é que a partir do século XVII há uma mudança na gestão do poder (Foucault, 2009b; Martins \& Peixoto, 2009). A preocupação deixa de ser com a morte dos indivíduos - isto é, o direto do soberano se apoderar da vida para extingui-la (pedindo a seus súditos que tomem parte na defesa de um Estado, por exemplo) - e passa a ser dirigida ao poder de aprimorar a força produtiva dos corpos, fazê-los crescer, ordená-los, adestrá-los, integrando-os cada vez mais ao sistema capitalista - ou seja, passa a se preocupar e ocupar-se com a vida. $\mathrm{O}$ efeito é uma aliança da medicina - que antes se ocupava somente das doenças e dos doentes, com o Estado, em uma progressiva normalização e medicalização do Estado, da sociedade e, de sua população (Foucault, 2008b).

O que percebemos, portanto, é um uso do poder, advindo da condição de pacientes, pelos usuários do sistema de atenção à saúde mental. Trata-se de uma ação política que desconhece sua causa e os possíveis modos alternativos de subjetivação, resistência e luta por direitos civis. Mas como nos lembrou Arendt (2010, p. 98): "esperar de pessoas que não têm a menor noção acerca do que é a res publica, a coisa pública, que se comportem de maneira não violenta e discutam racionalmente em questões de interesse não é realista nem razoável". O que Alda confirma: "como é que você vai inserir alguém na realidade se a realidade é cheia de normas e ela desconhece todas elas?".

\section{A subjetivação psiquiátrica}

Cássia inicialmente nos aponta uma falta de preparo e formação dos psiquiatras para os novos dispositivos: "no modelo asilar era fácil: você trancava, você sedava, você amarrava e pronto. Nessa outra concepção não...". A identificação ao discurso psiquiátrico atual promove um impasse: "se eu não internar aqui, realmente não tem nada para eu fazer. Como é 
que você bota a pessoa pra fora? Não tenho capacidade pra fazer isso", diz Aline. Célio diz mais:

muitos chegam lá em uso de medicamentos, e como é que você vai tirar? Quê que você vai colocar no lugar do medicamento? Quê que você vai oferecer? Esse é o problema. Você não tem o que oferecer no lugar da medicação. Então a gente fica de mãos atadas.

Célio diz que ainda acha que o hospital é o lugar para o tratamento da psicose "até por falta de outras opções, que nos ofereçam outras opções", e é importante marcar que o entrevistado não desconhece a existência dos serviços substitutivos. A opção que ele não encontra nesses dispositivos da reforma é a permanência do discurso psiquiátrico como tal, evidenciando certo mal-estar com a atual política, sentida como excludente para o psiquiatra.

Finalmente, relembraríamos a fala de Alda:

todas as atrocidades que foram cometidas, como falava Helvécio Ratton, “em nome da razão"... essas não acontecem mais. Acontecem outras. Eu acho que às vezes tem violências tão ou idênticas aquelas. ... Quando é que a gente vai recolher em relação à reforma as questões contemporâneas dessa violência instituída que está ai?

\section{Considerações finais}

\section{O modelo Eichmanniano de subjetivação}

Vimos delinear-se uma postura que aqui chamamos de modelo eichmanniano, inspirados pela análise do julgamento de Eichmann feita por Arendt (1999). Eichman foi o tenente-coronel da SS nazista responsável pelo transporte e emigração de judeus em direção aos campos de concentração durante o período do terceiro reich. Preso e deportado da Argentina, seu julgamento ocorre de abril a dezembro de 1961 em Israel. Hannah Arendt acompanhou o processo e se surpreendeu, pois pensava que iria encontrar no acusado um monstro, figura que encarnaria o mal nazista, assassino frio e cruel. Porém, para a surpresa dos presentes, deparou-se com um burocrata, alguém que em determinado momento passou a não mais ter consciência do mal que fazia ao outro. A situação havia se tornado o exercício cotidiano de um mal banal donde se consagrou a expressão "banalidade do mal", efeito de superficialidade da ausência de pensamento do acusado (Souki, 2006). Arendt aponta como Eichmann tinha opção de agir de outro modo, mas não chegou a cogitar fazê-lo. Seguiu as ordens, não questionando o discurso do nazismo: "não era estupidez, mas irreflexão", disse Arendt (1991, p.6).

Sabemos que os entrevistados não são sujeitos que buscam o "mal" para os seus pacientes. E nem os paciente são "aproveitadores" dos benefícios sociais decorrentes de sua condição. São sujeitos que se subjetivaram através do poder psiquiátrico. Verificamos que já não se trata mais da exclusão sistemática da loucura, mas de sua forçosa inclusão nos modelos de subjetivação normativos, reafirmando a passagem do modelo disciplinar ao modelo da biopolítica. Concordamos com Foucault quando ele disse: "Como o poder seria leve e fácil, sem dúvida, de desmantelar se ele não fizesse senão vigiar, espreitar, surpreender, interditar e punir; mas ele incita, suscita, produz; ele não é simplesmente orelha e olho; ele faz agir e falar." (Foucault, 2006c, pp. 219-220).

Percebemos como práticas violentas ainda são exercidas e legitimadas pelo discurso psiquiátrico. Porém, Arendt nos apontou que "a violência aparece onde o poder está em risco" (2010, p. 73), e esse fato nos faz questionar a permanência do discurso asilar como uma modalidade de poder médico, em uma sociedade que já sofre os efeitos da reforma psiquiátrica. Porém, pensamos que do lado dos pacientes o decréscimo de poder pela carência da capacidade de agir juntos é um convite à violência.

Foucault (1995) afirmou que "talvez o objetivo hoje em dia não seja descobrir o que somos, mas recusar o que somos" (p. 239). Desse modo, pensamos ser possível criar espaços para o surgimento de novos modos de subjetivação. Deleuze (2010, p. 139) nos indicou como a subjetivação foi a terceira grande categoria encontrada por Foucault para sair do impasse dos labirintos da analítica do poder.

Assim, como nos disse ainda Foucault (1995, p. 239):

A conclusão seria que o problema político, ético, social e filosófico de nossos dias não consiste em tentar liberar o indivíduo do Estado, nem das instituições do Estado, porém nos liberarmos tanto do Estado quanto do tipo de individualização que a ele se liga. Temos que promover novas formas de subjetividade através da recusa desse tipo de individualidade que nos foi imposto há vários séculos.

Barreto (2008) retoma o conceito de cidadania e comunidade e elucida como a reforma psiquiatria ainda é tímida com relação à acepção e potência dos termos. Dessa forma,

um programa de reabilitação que, não obstante suas melhores intenções, tome para si a tarefa de 'humanizar' o controle técnico sobre a experiência da loucura, não cumprirá propriamente qualquer ação política, limitando-se a táticas mais ou menos sofisticadas de reposição do jogo social. (Barreto, 2008, p. 312)

Confirma-se, portanto, a importância da potência política de um movimento de resistência popular, força que a reforma psiquiatria deve retomar, buscando novas formas de sociabilidade que não se conformem com a 
reprodução de lógicas totalitárias de inserção social, reinventando espaços coletivos para o exercício político entre homens iguais, valendo-se da amizade e da liberdade. Trata-se de um novo exercício político e um novo desafio à reforma psiquiátrica.

\section{Nota}

* Apoio CNPq

\section{Referências}

Arendt, H. (1991). A vida do espírito: o pensar, o querer, o julgar. Rio de Janeiro: Relume-Dumará.

Arendt, H. (1999). Eichmann em Jerusalém: um relato sobre a banalidade do mal. São Paulo: Companhia das Letras.

Arendt, H. (2010). Sobre a violência (2 ${ }^{\mathrm{a}}$ ed.). Rio de Janeiro: Civilização Brasileira.

Barreto, J. (2008). Cidadania, subjetividade e reforma psiquiátrica. Physis: Revista de Saúde Coletiva, 18(2), 295-316.

Bertolote, J. M. (2009). Violência e saúde mental: como podemos fazer parte da solução? Revista Brasileira de Psiquiatria, 31(supl. 2), 39-40.

Charaudeau, P. (2008). Linguagem e discurso: modos de organização. São Paulo: Contexto.

Charaudeau, P. \& Maingueneau, D. (2008). Dicionário de análise do discurso. São Paulo: Contexto.

Conselho Nacional de Saúde. (2001). Resolução 196/96. Brasília, DF: Autor.

Costa, J. F. (1986). Violência e psicanálise (2a ed.). Rio de Janeiro: Ed. Graal.

Delgado, P. G. G. (1992). As razões da tutela: Psiquiatria, justiça e cidadania do louco no Brasil. Rio de Janeiro: Te Corá.

Deleuze, G. (2010). Conversações (1972-1990) (2ª ed.). São Paulo: Ed. 34.

Deslandes, S. F. \& Gomes, R. (2004). A pesquisa qualitativa em serviços de saúde: notas teóricas. In M. L. M. Bosi \& F. J. Mercado (Orgs.), Pesquisa qualitativa de serviços de saúde (pp. 99-120). Petrópolis, RJ: Vozes.

Duarte, A. (2010). Poder e violência no pensamento político de Hannah Arendt: uma consideração. In H. Arendt, Sobre a violência ( $2^{\mathrm{a}}$ ed., pp. 131-137). Rio de Janeiro: Civilização Brasileira.

Fontanella, B. J. B., Ricas, J., \& Turato, E. R. (2008, janeiro). Amostragem por saturação em pesquisas qualitativas em saúde: contribuições teóricas. Cadernos de Saúde Pública, 24(1), 17-27.

Foucault, M. (1995). O sujeito e o poder. In H. L. Dreyfus \& P. Rabinow, Michel Foucault uma trajetória filosófica: para além do estruturalismo e da hermenêutica (pp. 231-249). Rio de Janeiro: Forense Universitária.

Foucault, M. (2000). História da loucura na idade clássica (6 ${ }^{\mathrm{a}}$ reimp.). São Paulo: Ed. Perspectiva.

Foucault, M. (2002). Os anormais: Curso no Collège de France (1974-1975). São Paulo: Martins Fontes.

Foucault, M. (2006a). Problematização do sujeito: psicologia, psiquiatria e psicanálise (Ditos \& Escritos I, 2ª ed.). Rio de Janeiro: Forense Universitária.

Foucault, M. (2006b). O poder psiquiátrico: Curso dado no Collège de France (1973-1974). São Paulo: Martins Fontes.
Foucault, M. (2006c). Estratégia, poder-saber (Ditos \& Escritos IV, $2^{\text {a }}$ ed.). Rio de Janeiro: Forense Universitária.

Foucault, M. (2008a). Arqueologia do saber ( $7^{\mathrm{a}}$ ed., $3^{\mathrm{a}}$ reimp.). Rio de Janeiro: Forense Universitária

Foucault, M. (2008b). Nascimento da biopolítica: Curso dado no Collège de France (1978-1979). São Paulo: Martins Fontes.

Foucault, M. (2009a). Microfisica do poder (27 ${ }^{\mathrm{a}}$ reimp.). Rio de Janeiro: Ed. Graal.

Foucault, M. (2009b). História da sexualidade I: a vontade de saber (19 ed.). Rio de Janeiro: Ed. Graal.

Foucault, M. (2010). Ética, sexualidade, política (Ditos \& Escritos V, $2^{\text {a }}$ ed.). Rio de Janeiro: Forense Universitária.

Goulart, M. S. B. (2006) A construção da mudança nas instituições sociais: a reforma psiquiátrica. Pesquisas e práticas psicossociais, 1(1), 1-19.

Goulart, M. S. B. \& Durães, F. (2010). A reforma e os hospitais psiquiátricos: histórias de desinstitucionalização. Psicologia \& Sociedade, 22(1), 112-120.

Grandella, O., Jr. (2002, janeiro/junho). Hospital psiquiátrico (re)afirmação da exclusão. Psicologia \& Sociedade, 14(1), 87-102.

Machado, R. (2009). Por uma genealogia do poder. In M. Foucault, Microfisica do poder (pp. VII-XXIII). Rio de Janeiro: Ed. Graal.

Maia, A. (1995, outubro). Sobre a analítica de poder de Foucault. Tempo social: Revista de Sociologia, 7(1-2), 83-103.

Maingueneau, D. (1997). Novas tendências em análise do discurso ( $3^{\mathrm{a}}$ ed.). Campinas, SP: Pontes/Editora da Universidade Estadual de Campinas.

Martins, A. L. B. (2008). Biopsiquiatria e bioidentidade: política da subjetividade contemporânea. Psicologia \& Sociedade, 20(3), 331-339.

Martins, L. A. M. \& Peixoto, C. A., Jr. (2009). Genealogia do biopoder. Psicologia \& sociedade, 21(2), 157-165.

Minayo, M. C. S. (1994). A violência sob a perspectiva da saúde pública. Cadernos de Saúde Pública, 10(supl. 1), 07-18.

Minayo, M. C. S. (2008). O desafio do conhecimento: pesquisa qualitativa em saúde (11 a ed.). São Paulo: Hucitec.

Minayo, M. C. S. \& Souza, E. R. (1997-1998). Violência e saúde como um campo interdisciplinar de ação coletiva. História, Ciências, Saúde - Manguinhos, 4(3), 513-531.

Ministério da Saúde. (2010, junho). Saúde Mental em Dados, ano 5, 7. Informativo eletrônico. Acesso em 02 de outubro, 2010, em http://portal.saude.gov.br/portal/arquivos/pdf/ smdados.pdf

Moretzsohn, J. A. (1989). História da psiquiatria mineira. Belo Horizonte: Coopmed.

Krug, E. G., Dahlberg, L. L., Mercy, J. A., Zwi, A. B., \& Lozano, R. (Eds.). (2002). Relatório Mundial sobre saúde e violência. Genebra: Organização Mundial de Saúde.

Organização Pan-Americana da Saúde, Organização Mundial da Saúde. (2001). Relatório sobre a saúde no mundo 2001: saúde mental: nova concepção, nova esperança. Brasília: Autor.

Ortega, F. (2003, setembro/2004, fevereiro). Biopolíticas da saúde: reflexões a partir de Michel Foucault, Agnes Heller e Hannah Arendt. Interface - Comunicação, Saúde, Educação, $8(14), 9-20$.

Passos, I. C. F. (Org.). (2008). Poder, normalização e violência: incursões foucaultianas para a atualidade (Coleção Estudos Foucaultianos). Belo Horizonte: Ed. Autêntica.

Passos, I. C. F. (2009). Loucura e sociedade: discursos, práticas e significações sociais. Belo Horizonte: Argvmentvm. 
Passos, I. C. F. (2010). Violência e relação de poder. Rev. Med. Minas Gerais, 20(2), 234-241.

Passos, I. C. F., Goulart, M. S. B., Braga, F. M., Abreu, M. A., \& Vasconcelos, E. M. (2009). A formação em psicologia da Universidade Federal de Minas Gerais e o processo de reforma psiquiátrica em Minas Gerais, nas décadas de 60, 70 e 80. Memorandum, 17, 149168. Acesso em 27 de outubro, 2010, em http:/www.fafich.ufmg.br/ memorandum/a17/ passosecol01.pdf

Ratton, H. (1979). Em nome da razão [filme-vídeo]. Vidigal, T. Prod. Belo Horizonte: Associação Mineira de Saúde Mental. VHS/NTSC, 24 min. p/b. son.

Rocha, D. \& Deusdará, B. (2005, julho/dezembro). Análise de conteúdo e análise de discurso: aproximações e afastamentos na (re)construção de uma trajetória. Alea, 7(2), 305-322.

Roudinesco, E., Canguilhem, G., Major, R., \& Derrida, J. (1994). Foucault: leituras da história da loucura. Rio de Janeiro: Relume-Dumará.

Sistema Único de Saúde, Conselho Nacional de Saúde. (2002). Relatório Final da III Conferência Nacional de Saúde Mental. Brasília, 11 a 15 de dezembro de 2001. Brasília, DF: Conselho Nacional de Saúde/Ministério da Saúde.

Souki, N. (2006). Hannah Arendt e a banalidade do mal (1 ${ }^{\text {a }}$ reimp.). Belo Horizonte: Editora UFMG.

Recebido em: 30/11/2010

Revisão em: 04/08/2011

Aceite em: 14/09/2011
Bernardo Malamut é Psicólogo, Psicanalista, Mestre em Ciências da Saúde no Centro de Pesquisas René Rachou/FIOCRUZ. Endereço: R. Paraíba, 1352, sala 908. Funcionários. Belo Horizonte/MG, Brasil. CEP 30130-141. Email: bernardomalamut@gmail.com

Celina Maria Modena é Psicóloga, Doutora em Ciências, Pós-doutora em Saúde Coletiva pela FIOCRUZ. Professora do Programa de Pós-graduação do CPQRR/FIOCRUZ e pesquisadora visitante FAPEMIG/FIOCRUZ-MG.

Izabel Friche Passos é Psicóloga, Doutora em Psicologia Clínica pela PUC-SP. Professora associada do Departamento de Psicologia e do Programa de Pósgraduação em Psicologia da Universidade Federal de Minas Gerais.

\section{Como citar:}

Malamut, B., Modena, C. M., \& Passos, I. F. (2011). Violência e poder no discurso psiquiátrico: da exclusão sistemática às subjetivações normativas. Psicologia \& Sociedade, 23(n. spe.), 53-62. 